\title{
Image Enhancement using Modified Histogram Equalization with DSIHE
}

\author{
Ribana $\mathbf{K}^{1}$ \\ Assistant Professor, Department of ECE, M. Kumarasamy College of Engineering, Karur, India ${ }^{1}$
}

\begin{abstract}
Enhancing is the process can be done in many ways for obtaining more details from the images that can be attain by image extraction, contrast enhancement, denioising and dehazing are the various techniques for the image enhancement. In our paper the enhancement is obtain with the help of contrast enhancement technique. Improving the contrast is the process of introducing necessary difference between the pixel values of an input image to obtain more informative output image. The proposed algorithm is done by modifying the original image histogram and performs histogram equalization then the final image obtained by combining the histogram equalized image with DSIHE image.
\end{abstract}

Keywords: contrast enhancement, dehazing, filtering, denioising.

\section{INTRODUCTION}

The modification of histogram equalization techniques have been introduced for eliminating the drawbacks present in the traditional technique some drawbacks of histogram equalization technique is noted here it produces over enhancement due to the equalized output histogram and introduces more noise in an output image because of under and over enhancement[1].The modification of histogram equalization gives the way to introduce new modification technique with minimum noise and acceptable enhancement and visual quality at the output.

The initial modification is obtained from the mean value of an image that will be use full for dividing the histogram of original image and that divided histograms are under gone to histogram equalization technique this technique is named as Bi-Histogram Equalization (BBHE)[2].The median value is taken as the parameter for dividing the image histogram that is be named as Dualistic Sub image Histogram Equalization (DSIHE)[3].The local mean value calculation is produce Recursive Sub image Histogram Equalization(RSIHE)[4].

\section{PREVIOUS WORK}

This part describes previous algorithms and methods for contrast enhancement in the literature

\section{A. Histogram Equalisation (HE)}

Widely using technique for contrast enhancement application is histogram equalization. The enhancement can derived in three steps by using this algorithm the initial step is the calculation of histogram using Probability Density Function. From that the CDF is calculated by cumulatively adding PDF. The final image transformation is obtained by multiplying the CDF with the difference between the maximum and minimum pixel values and add the value with minimum pixel value in the input image.
B. Brightness Preserving Bi-Histogram Equalization (BBHE)

The input image histogram is calculated by using PDF value then it is compared with the mean value of an input image when histogram is having lesser value compared to the mean it is separated as one histogram the remaining pixel values are used to compute the another histogram the final image is calculated by equalizing the histogram separately by histogram equalization technique then it will be added to get the output image.

C. Dualistic Sub-Image Histogram Equalization (DSIHE) The procedure for attaining this algorithm is as similar to the BBHE algorithm but the separation of the image histogram is calculated by median value of an original image.

\section{Gamma Correction (GC)}

A gamma correction technique changes the pixel values of an image by varying the exponential value (i.e) gamma [10]. The gamma correction is obtained by,

$$
\mathrm{T}(\mathrm{k})=\mathrm{k}_{\max } \times\left(\frac{\mathrm{k}}{\mathrm{k}_{\max }}\right)^{\gamma}
$$

The contrast of an image is improving in a better way but the enhancement is not depends on the input pixel values it enhances the image in a similar way.

\section{PROPOSED ALGORITHM}

In the literature review about the enhancement algorithm clearly shows that the algorithm can produce better enhancement but it cannot attain the minimum brightness error as well as considerable PSNR value for attain that in our proposed algorithm the original image histogram is modified as

$$
\mathrm{H}_{\text {modified }}=\theta \mathrm{H}+(1-\theta) \mathrm{H}_{\mathrm{u}}
$$


The modified histogram is generated by adding the original image histogram with uniform histogram for producing the better visual quality as well as better enhancement the enhancement level is controlled by the parameter $\theta$.the value of $\theta$ is maintained as 0.5 for smooth enhancement of an image. After producing the modified histogram equalization the DSIHE of original image is fused with modified histogram equalized image the output image can produce better enhancement when compared with the existing algorithms. The fusion of images can be calculated through DWT of modified histogram equalization image and DSIHE image. Each band of the two images is fused by the fusion technique for producing the final image. Then IWDT have been taken for maintaining the originality of an image.DWT is preferred for separating the bands because it can produce perfect inversion at the output. The algorithmic steps as follows,

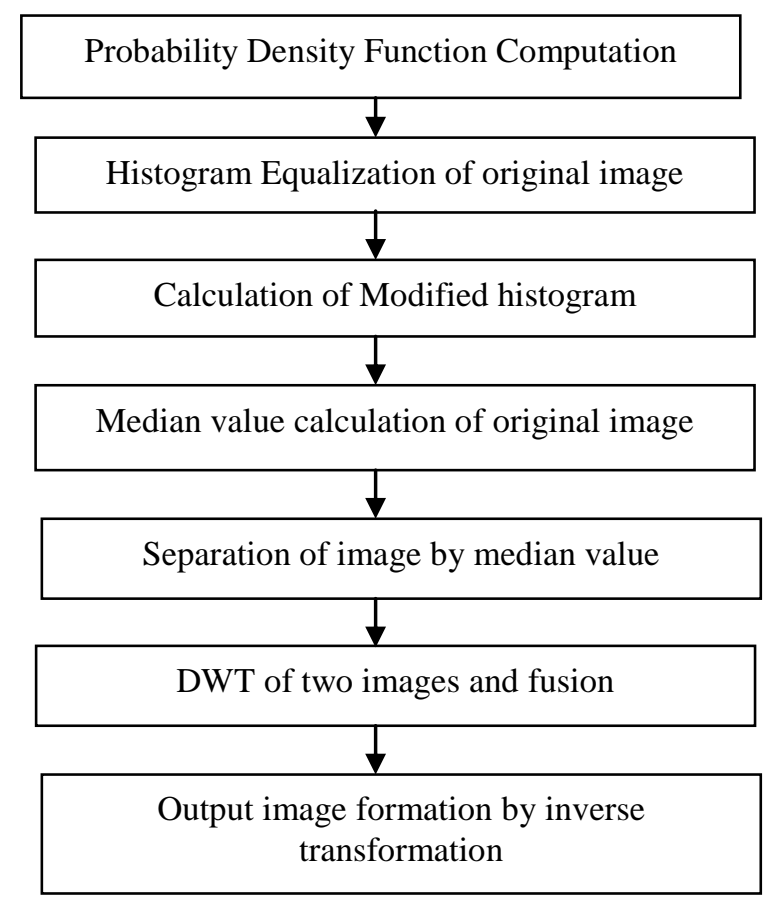

Fig1 Proposed algorithm steps

\section{IV.RESULT AND DISCUSSION}

The proposed algorithm is performed using MATLAB2013a.and it is compared with the existing algorithms HE, BBHE, DSIHE, and GC. The proposed algorithm is compared with the existing

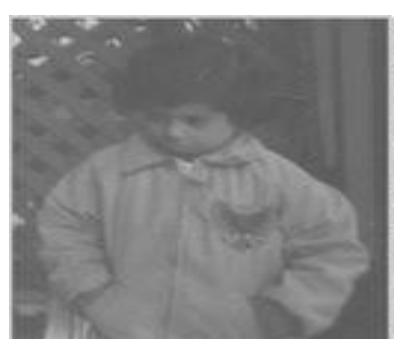

(a)

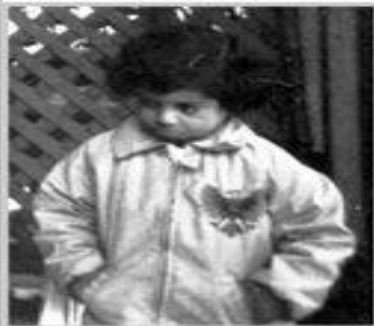

(b)

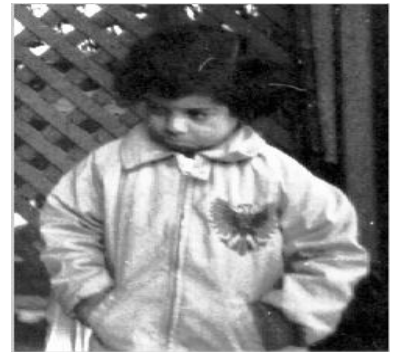

(c)

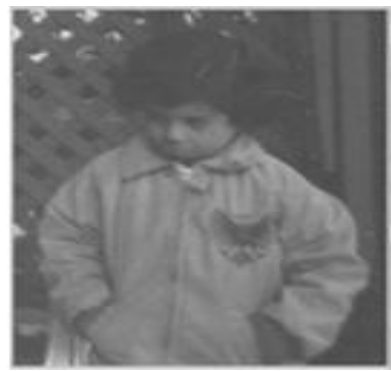

(e)

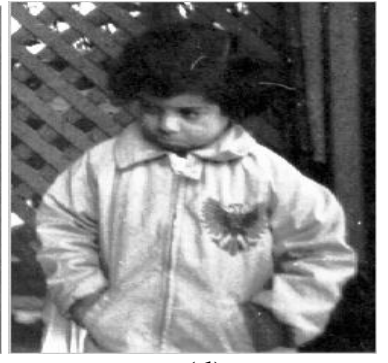

(d)

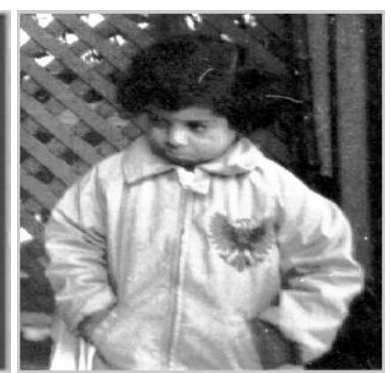

(f)
Fig. 2 . Simulation results of HE, BBHE,DSIHE, GC,AGC and proposed algorithms (a) Original image (b) Histogram Equalised image (c) Brightness Preserving Bi-Histogram Equalised image (d) Dualistic Sub Image Histogram Equalisation (e) Gamma corrected image (f) Proposed Image.

TABLE 1 Peak Signal to Noise Ratio (PSNR) For HE, BBHE, DSIHE, GC and proposed algorithms

\begin{tabular}{|l|c|}
\hline \multicolumn{1}{|c|}{ ENHANCEMENT METHODS } & PSNR(dB) \\
\hline Histogram Equalisation & 16.19 \\
\hline $\begin{array}{l}\text { Brightness Preserving Bi-Histogram } \\
\text { Equalisation }\end{array}$ & 17.28 \\
\hline $\begin{array}{l}\text { Dualistic Sub-Image Histogram } \\
\text { Equalisation }\end{array}$ & 18.24 \\
\hline Gamma Correction & 16.17 \\
\hline Propded algorithm & 34.27 \\
\hline
\end{tabular}

TABLE 2 Mean Square Error (MSE) For HE, BBHE, DSIHE, GC and Proposed agorithm

\begin{tabular}{|l|c|}
\hline \multicolumn{1}{|c|}{ ENHANCEMENT METHODS } & AMBE \\
\hline HistogramEqualisation & 109.30 \\
\hline $\begin{array}{l}\text { Brightness Preserving Bi-Histogram } \\
\text { Equalisation }\end{array}$ & 55.15 \\
\hline $\begin{array}{l}\text { Dualistic Sub Image Histogram } \\
\text { Equalisation }\end{array}$ & 20.84 \\
\hline Gamma Correction & 46.53 \\
\hline Proposed algorithm & 42.37 \\
\hline
\end{tabular}

\section{CONCLUSION AND FUTURE WORK}

The proposed algorithm is compared with existing methods it performs well by providing better results and visual presentation it can be modified for color images and 
the algorithm can be modified and extended for ultrasound images for medical applications.

\section{REFERENCES}

[1] S D.Chen A.Ramli 'Minimum Mean Brightness Error Bi-Histogram Equalization In Contrast Enhancement', IEEE Transactions on Consumer Electronics, Vol. 49, No. 4, pp.1310-1319, 2003.

[2] S.Palanivel Rajan, "Diagnosis of Cardiovascular Diseases using Retinal Images through Vessel Segmentation Graph", Current Medical Imaging Reviews, Online ISSN: 1875-6603, ISSN: 15734056, Vol. : 13, DOI : 10.2174/1573405613666170111153207, 2017

[3] R.Gonzalez and R.Woods. 'Digital Image Processing, 2nd edition'. Prentice Hall,1997.

[4] S C. Huang F C. Cheng and Y S. Chiu 'Efficient Contrast Enhancement Using Adaptive Gamma Correction with Weighting Distribution', IEEE Transactions. Image Processing, Vol. 22, issue: 3, pp. 1032-1041, 2013.

[5] Y. Kim 'Contrast enhancement using brightness preserving bihistogram equalization', IEEE Transactions. Consumer Electronics, Vol. 43, No. 1, pp. 1-8, 1997.

[6] V Kavitha, V Palanisamy, 'New Burst Assembly and Scheduling T technique for Optical Burst Switching Networks', Journal of Computer Science, Vol. 9, Issue 8, pp.1030-1040, 2013.

[7] $\mathrm{C} \mathrm{H}$ Ooi. and $\mathrm{N} \mathrm{A}$. Mat Isa 'Adaptive Contrast Enhancement Methods with Brightness Preserving', IEEE Transactions on Consumer Electronics, Vol. 56, No. 4 pp. 2543-2551. 2010.

[8] S Palanivel Rajan, "Review and Investigations on Future Research Directions of Mobile Based Tele care System for Cardiac Surveillance", Journal of Applied Research and Technology, Vol.13, Issue 4, pp.454-460, 2015.

[9] S Palanivel Rajan, M Paranthaman C,Vivek, "Design and Enhancement of Wideband Reconfigurability using Two E-Shaped Patch Antenna", Asian Journal of Research in Social Sciences and Humanities, ISSN : 2249-7315, Vol.6, Issue 9, pp. 317-327, 2016.

[10] S Palanivel Rajan, "A Significant and Vital Glance on "Stress and Fitness Monitoring Embedded on a Modern Telematics Platform", Telemedicine and e-Health Journal, Vol.20, Issue 8, pp.757-758, 2014

111] S Palanivel Rajan, T Dinesh, "Systematic Review on Wearable Driver Vigilance System with Future Research Directions", International Journal of Applied Engineering Research, Vol. 2, Issue 2, pp.627-632, 2015

[12] S Palanivel Rajan, S Vijayprasath, "Performance Investigation of an Implicit Instrumentation Tool for Deadened Patients Using Common Eye Developments as a Paradigm", International Journal of Applied Engineering Research, Vol.10, Issue 1, pp.925-929, 2015.

[13] N Sengee. A Sengee. and H K. Choi 'Image Contrast Enhancement using Bi-Histogram Equalization with Neighborhood Metrics', IEEE Transactions on Consumer Electronics, Vol. 56, No. 4, pp. 2727-2734,2010.

[14] K S Sim. C P Tso. and Y. Tan 'Recursive sub-image histogram equalization applied to gray-scale images', Pattern Recognition. Letter, Vol. 28, pp. 1209-1221, 2007.

[15] Tarik Arici, Salih Dikbas 'A Histogram Modification Framework and Its Application for Image Contrast Enhancement',IEEE Transactions on Image Processing ,Vol. 18, No. 9, pp. 1921-1935, 2009.

[16] C Vivek, S Palanivel Rajan, "Z-TCAM : An Efficient Memory Architecture Based TCAM", Asian Journal of Information Technology, Vol.15, Issue 3, pp.448-454, 2016.

[17] C Vivek, S Palanivel Rajan, "Design of Data Aware Low Power Area Efficient Datapaths for Processing Elements in a Reconfigurable System", International Journal of Computer Science and Information Security, ISSN : 1947-5500, Vol.14, Issue 9, pp. 1100-1113, 2016

18] S.Palanivel Rajan, T.Dinesh, "Analysis of Human Brain Disorders for Effectual Hippocampus Surveillance", International Journal of Modern Sciences and Engineering Technology, ISSN 2349-3755, Vol. No.: 2, Issue No.: 2, pages: 38-45, 2015.
[19] S.Palanivel Rajan, K.Sheik Davood, "Performance Evaluation on Automatic Follicles Detection in the Ovary", International Journal of Applied Engineering Research, ISSN No.: 0973- 4562, Vol. 10, Issue 55, pp. 1-5, 2015

[20] S.Palanivel Rajan, R.Sukanesh, "Experimental Studies on Intelligent, Wearable and Automated Wireless Mobile Tele-Alert System for Continuous Cardiac Surveillance", Journal of Applied Research and Technology, ISSN No.: 1665-6423, Vol. No. 11, Issue No.: 1, pp.133-143, 2013

[21] S.Palanivel Rajan, R.Sukanesh, S.Vijayprasath, "Analysis and Effective Implementation of Mobile Based Tele-Alert System for Enhancing Remote Health-Care Scenario", HealthMED Journal, ISSN No. : 1840-2291, Vol. No. 6, Issue 7, pp. 2370-2377, 2012.

[22] S.Palanivel Rajan, R.Sukanesh, S.Vijayprasath, "Design and Development of Mobile Based Smart Tele-Health Care System for Remote Patients", European Journal of Scientific Research, ISSN No.: 1450-216X/1450-202X, Vol. No. 70, Issue 1, pp. 148-158, 2012.

[23] S.Palanivel Rajan, Sukanesh, R, et.al., "Performance Analysis Of Mobile Phone Radiation Minimization Through Characteristic Impedance Measurement", International Journal of Computer Science Issues, Vol. 9, Issue 2, p540, 2012.

24] C Vivek, S Palanivel Rajan, V Kavitha, "Implementation of High Speed Area Efficient Variable Latency Adder", Asian Journal of Research in Social Sciences and Humanities, Vol. 6, Issue : 9, pp.306-316, 2016.

[25] S.Palanivel Rajan, R.Sukanesh, "Viable Investigations and Real Time Recitation of Enhanced ECG Based Cardiac Tele-Monitoring System for Home-Care Applications: A Systematic Evaluation”, Telemedicine and e-Health Journal, ISSN: 1530-5627, Online ISSN: 1556-3669, Vol. No.: 19, Issue No.: 4, pp. 278-286, 2013.

[26] S.Palanivel Rajan, et.al., "Intelligent Wireless Mobile Patient Monitoring System”, IEEE Digital Library Xplore, ISBN No. 978 1-4244-7769-2, INSPEC Accession Number: 11745297, IEEE Catalog Number: CFP1044K-ART, pp. 540-543, 2010.

[27] S.Palanivel Rajan, et.al., "Cellular Phone based Biomedical System for Health Care", IEEE Digital Library Xplore, ISBN No. 978-14244-7769-2, INSPEC Accession Number: 11745436, IEEE Catalog Number: CFP1044K-ART, pp.550-553, 2010.

[28] S.Palanivel Rajan, et.al., "Performance Evaluation of Mobile Phone Radiation Minimization through Characteristic Impedance Measurement for Health-Care Applications", IEEE Digital Library Xplore, ISBN : 978-1-4673-2047-4, IEEE Catalog Number: CFP1221T-CDR, 2012

[29] S.Palanivel Rajan, et.al., "Experimental Explorations on EOG Signal Processing for Real Time Applications in LabVIEW", IEEE Digital Library Xplore, ISBN : 978-1-4673-2047-4, IEEE Catalog Number: CFP1221T-CDR, 2012.

[30] S.Palanivel Rajan, et.al., "Visual and tag-based social image search based on hypergraph ranking method", IEEE Digital Library Xplore, ISBN : 978-1-4799-3835-3, INSPEC Accession Number : 14916051, DOI : 10.1109/ICICES.2014.7034079, 2015.

[31] Agnus Swarnanisha Lakshmi, S.Palanivel Rajan, "Scheduled H and X Medicine Dispenser PoC Design", Journal of Chemical and Pharmaceutical Sciences, ISSN No.: 0974-2115, Special Issue : 8, pp. 1-4, 2016

[32] S. Palanivel Rajan, C.Vivek, "Blending Augmented Reality and Cloud - Need of the hour and an innovative approach", Journal of Chemical and Pharmaceutical Sciences, ISSN No.: 0974-2115, Special Issue : 8, pp. 23-27, 2016.

[33] S. Palanivel Rajan, M.Poovizhi, "Design of Patch Antenna Array for Radar Communication", Journal of Chemical and Pharmaceutical Sciences, ISSN No.: 0974-2115, Special Issue : 8, pp. 38-40, 2016.

[34] C.Vivek, S. Palanivel Rajan, "Review of Low Power and High Speed Implementation of 3-bit Flash Analog to Digital Converter", Journal of Chemical and Pharmaceutical Sciences, ISSN No.: 09742115, Special Issue : 8, pp. 74-78, 2016.

[35] S.Palanivel Rajan, C.Vivek, M.Paranthaman, "Feasibility Analysis of Portable Electroencephalography Based Abnormal Fatigue Detection and Tele-Surveillance System", International Journal of Computer Science and Information Security, ISSN No.: 1947-5500, Vol. No.: 14, Issue: 8, pp. 711-722, 2016. 